\title{
Feingold syndrome type 1
}

INSERM

\section{Source}

INSERM. (1999). Orphanet: an online rare disease and orphan drug data base. Feingold syndrome type 1. ORPHA:391641

Feing old syndrome type 1 (FS1) is a rare inherited malformation syndrome characterized by microcephaly, short stature and numerous digital anomalies. 